\title{
THE EFFECT OF FOREST FRAGMENTATION ON TREE SPECIES ABUNDANCE AND DIVERSITY IN THE EASTERN ARC MOUNTAINS OF TANZANIA
}

\author{
OJoYi, M. ${ }^{1}{ }^{*}$ - MutAnga, O. ${ }^{1}$ - Odindi, J. ${ }^{1}$ - AyneKulu, E. ${ }^{2}$ - Abdel-RAhMAn, E. ${ }^{1}$ \\ ${ }^{I}$ School of Agricultural, Earth and Environmental Sciences, University of KwaZulu-Natal, \\ Private Bag X01, Scottsville, Pietermaritzburg 3209, South Africa \\ (phone: +27-332605779; fax: +27-332605344) \\ ${ }^{2}$ World Agroforestry Centre, P.O. Box 30677, Gigiri, Nairobi 00100, Kenya \\ (phone: +254 20 7224356; fax: +254 20 7224001) \\ *Corresponding author \\ e-mail: mercyojoyi@gmail.com \\ (Received $9^{\text {th }}$ July 2014; accepted $14^{\text {th }}$ Aug 2014)
}

\begin{abstract}
Habitat fragmentation is considered a threat to biodiversity conservation. Uluguru forest block, a section of the Eastern Arc Mountains in Tanzania remains highly vulnerable to fragmentation. However, to date, fragmentation effects on species abundance and diversity have not been investigated. This study aimed at investigating effects of fragmentation on species abundance and diversity in Uluguru forest block, Morogoro region, Tanzania. A RapidEye satellite image was analyzed using the maximum likelihood classifier (MLC) to map the fragmented forest. Remotely sensed variables with data on species diversity were modelled using the Generic Algorithm for Rule-Set Prediction (GARP) algorithm while fragmentation parameters were extracted using Fragstats software, which were then linked to species and edaphic factors. Results showed that species diversity was predicted better with customized environmental variables which recorded an Area Under Curve (AUC) of 0.89. The Poisson regression results showed that individual tree species responded differently to patch area dynamics, habitat status and soil nitrogen. Generally, the abundance of dominant species like Mytenus undata Thunb $(p<0.001)$, Zenkerella capparidacea (Taub.) J. Leon $(p<0.001)$ and Oxyanthus specious DC. $(p=0.023)$ decreased with a reduction in patch area. The present study suggests the need to integrate comprehensive plans and other intervention measures into long-term intervention initiatives.
\end{abstract}

Keywords: RapidEye, habitat fragmentation, soil, species abundance

\section{Introduction}

Species abundance and richness are important measures of biodiversity (Gould, 2000). They vary from one spatial range to another, which is a function of habitat heterogeneity (Kerr et al., 2001) fragmentation (Murcia, 1995; Benítez-Malvido and Martínez-Ramos, 2003; Echeverría et al., 2007; Hobbs et al., 2008) and modification (Osborne et al., 2001). Habitat modification interferes with ecosystem configuration (Stoms and Estes, 1993), species distribution and numbers (Griffiths and Lee, 2000), structural complexity of ecosystems and their functioning (Debinski et al., 1999), patch and landscape ecosystem processes (Didham, 2001) and alters the biological trait of individual species (Helm et al., 2006). It also interacts synergistically with anthropogenic threats (Laurance, 2007) interrupting species occurrence, composition and density (Stoms and Estes, 1993). Literature shows that habitat fragmentation also condenses habitat area coverage enhancing the species extinction debt (Bogich et al., 2012). By reducing the total habitat area requirements of species (Murcia, 1995; Fahrig, 2003; Echeverría et al., 2007), the rate of species extinction and endemism is enhanced 
(Burgess et al.; Burgess et al., 2001; Burgess et al., 2002; Adams et al., 2003; TØTTRUP et al., 2004). In low montane ecosystems, fragmentation is known to affect species loss due to deforestation (Hall et al., 2009). Various studies indicate significant variability in the abundance of alien invasive plant species, due to fragmentation. For instance, Mumbi et al. (2008b) showed that fragmentation affects the abundance of coprophilous fungi and algal blooms as a result reduction in the population of Podocarpus and Psychotria tree species.

The intensity of fragmentation is dependent on different factors (Benítez-Malvido and Martínez-Ramos, 2003; Fahrig, 2003; Echeverría et al., 2007). For instance, dynamics in land use and elevation has an effect on individual species (Murcia, 1995; Benítez-Malvido and Martínez-Ramos, 2003; Fahrig, 2003; Burgess et al., 2007b; Echeverría et al., 2007). It may also be a function of varying patch sizes (Echeverría et al., 2007) and structural complexity (Murcia, 1995; Benítez-Malvido and Martínez-Ramos, 2003; Fahrig, 2003; Fischer and B. Lindenmayer, 2006; Burgess et al., 2007b; Echeverría et al., 2007). However, the effect of fragmentation on tree species at local scales is not widely explored (Ylhäisi, 2004; Zotz and Bader, 2009). Whereas a series of studies have used bioclimatic variables to ecologically model species diversity (Pearson and Dawson, 2003; Martínez-Meyer et al., 2004; Thuiller et al., 2006), the validity of this approach, particularly at local scales, remains unresolved (Araújo and Luoto, 2007).

As aforementioned, habitat fragmentation is a threat to biodiversity and conservation (Achard et al., 2002; DeFries et al., 2002; Benítez-Malvido and Martínez-Ramos, 2003; Fahrig, 2003; Fischer and B. Lindenmayer, 2006; Burgess et al., 2007b; Echeverría et al., 2007; Hobbs et al., 2008). This is the case for the Eastern Arc Mountains in Tanzania, a highly ranked global biodiversity hotspot (Olson and Dinerstein, 1998), Hall, 2009). They host approximately 100 endemic vertebrates (10 mammals, 20 birds, 38 amphibians, 29 reptiles) and approximately 1500 plant species including, 68 tree endemics (Burgess et al., 2007b). Despite their global importance, the region remains highly vulnerable to anthropogenic influence (Burgess et al.; Erik Bjørndalen, 1992; Burgess et al., 2002). The extent of habitat loss and fragmentation has been deleterious (Newmark, 1998; Fjeldså, 1999; Hall et al., 2009; Swetnam et al., 2011). Key threats include settlements, logging, farming and urban sprawl (Burgess et al., 2007b), consequently, approximately $80 \%$ of forest cover has been lost in recent years (Hall et al., 2009). A substantial area and the highest number of extinct species were recorded in lowland montane forest between 1975 and 2000 (Hall et al., 2009).

A shift in an ecosystem's stability transforms it to an undesired state, compromising its capacity to support normal functions and increasing the rate of endemism and extinction (Şekercioğlu et al., 2004). Although species vary in their geographic occurrence, distribution and response to dynamic environmental conditions (Fischer et al., 2004), modelling their diversity is a prerequisite in conservation monitoring, planning and management (Carlson et al., 2007). This forms a basis for knowledge generation, specifically on species-habitat relationships in space, time and future risk management (Olson et al., 2014). To date, this subject remains unexplored in natural fragmenting ecosystems in Morogoro region, Tanzania (Hall et al., 2009).

In this context therefore, this study aimed at investigating how forest fragmentation affects species abundance and diversity in a heterogeneous landscape in the Uluguru forest block. Edaphic factors such as NPK, $\mathrm{Ph}$ and $\mathrm{C}$ were used as indicators to soil health (Solomon et al., 2000; Fageria, 2010). 


\section{Materials and methods}

\section{Study area}

Uluguru tropical forest is located at $\left(7^{\circ} 2^{\prime}-7^{\circ} 16^{\prime} \mathrm{S}\right)$ and $\left(38^{\circ} 0^{\prime}-38^{\circ} 12^{\prime} \mathrm{E}\right)$ in Tanzania (Figure 1) and forms part of the Eastern Arc Mountains blocks, which is a series of crystalline mountains in Kenya and Tanzania (Burgess et al., 1998; Olson and Dinerstein, 1998). The mountains range from lowland rain forests to elfin montane forests and are separated by lowlands whose origin is said to have been caused by faulting (Munishi et al., 2007). The area experiences bimodal rainfall in April and November, ranging from 2900-4000 mm on windward slopes and 1200-4000 mm on the leeward (Munishi et al., 2007). The Uluguru forest block (Figure 1) hosts approximately 135 plant species (Fjeldså, 1999; Burgess et al., 2007b), however, the forest cover has declined from $300 \mathrm{~km} 2$ in 1955 to $220 \mathrm{~km}^{2} 2000$ from. Consequently, Uluguru montane forest ecosystem is regarded to be highly vulnerable to fragmentation, negatively affecting species abundance and increasing risk of extinction of rare species like the Uluguru Bush Shrike (Burgess et al.; Bjorndalen, 1992; Erik Bjørndalen, 1992; Burgess et al., 2001; Burgess et al., 2002; Fuchs et al., 2005).

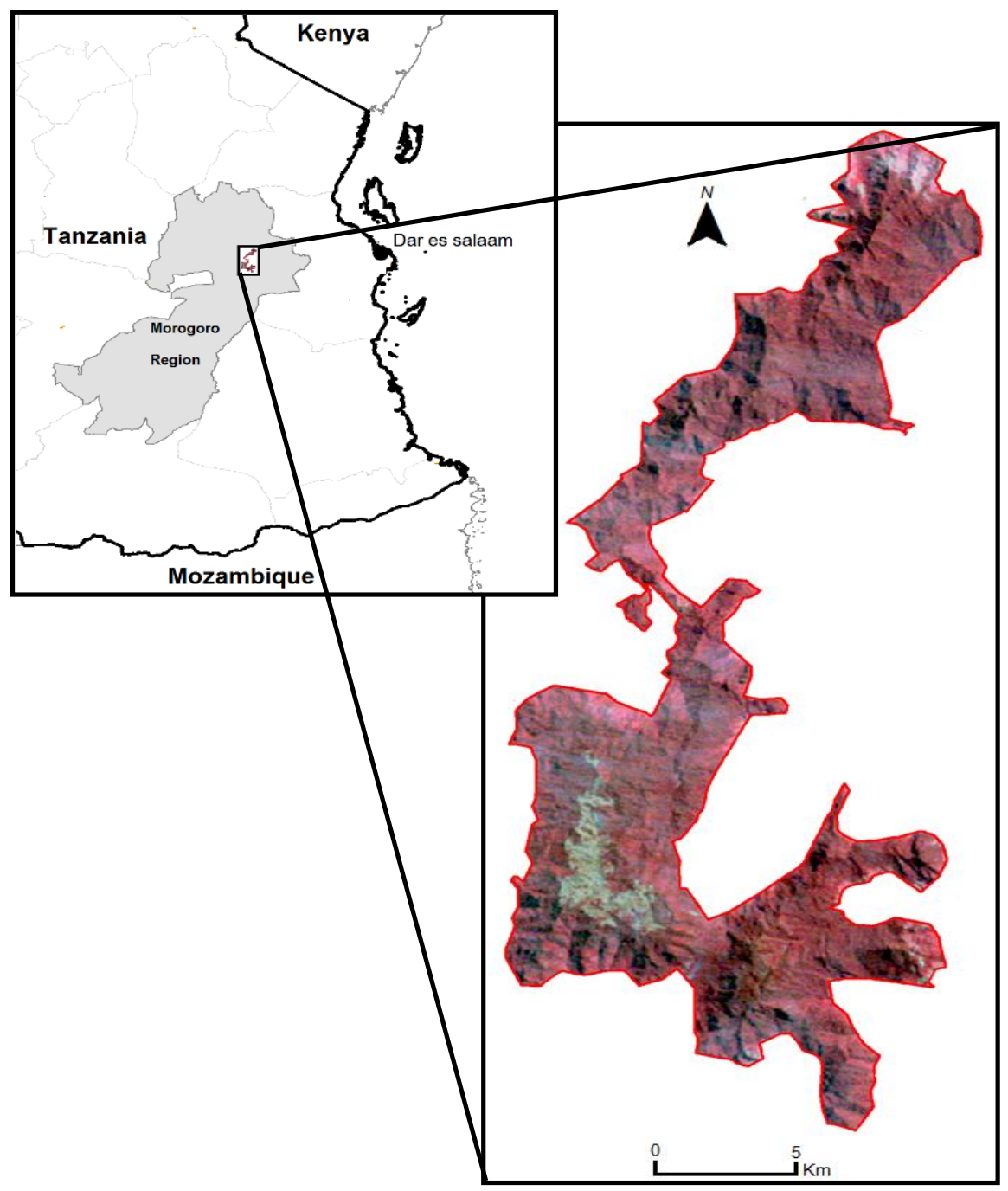

Figure 1. Location of Uluguru forest: delineation based on Landsat MSS captured in 1975 


\section{Field data collection}

Tree measurements were collected randomly within $10 \mathrm{~m} \times 10 \mathrm{~m}$ plots in August 2012, in the same month of image acquisition. Data was collected from 80 plots located in the field using a Global Positiong System (GPS) of submeter accuracy. Major tree species with more than five centimeters diameter at breast height $(\mathrm{dbh})$ were sampled. Data on species names, genera, families, density, basal height, and canopy cover were recorded. Additionally, elevation for each plot was taken. Soil data (C, N, P, pH and K) was collected within the $0-15 \mathrm{~cm}$ depth. The status of the habitat in Uluguru forest blocks was categorised into two classes; fragmmented and intact (82 data ground data points were used).

\section{Image acquisition and pre-processing}

RapidEye satellite imagery for the Uluguru forest block was acquired on 23/10/2012. RapidEye has a spatial resolution of 5 metre and 5 bands centered Blue: $440-510 \mathrm{~nm}$, Green: 520-590 nm, Red: 630-685 nm, Red Edge: 690-730 nm and NIR: 760-850 nm. The image was first geometrically corrected (Universal Transverse Mercator: UTM, zone 37 South projection) using 30 identifiable ground control points (GCPs) distributed across the image. The GCPs were recorded on 1:50000 topographic maps of various years. A nearest-neighbour algorithm and first order polynomial transformation were applied to resample the image to its original pixel size. The root mean square error of less than half a pixel was obtained, indicating a reliabe geometric correction. The imagery was then atmospherically corrected using ATCOR module built in Earth Resources Data Analysis System software (Erdas Imagine 2013) and digital number values converted to surface reflectance.

\section{Soil chemical analysis}

A total of 80 samples of soil taken at $0-15 \mathrm{~cm}$ depth were collected from $10 \mathrm{~m}$ by 10 $\mathrm{m}$ plots. Samples were air dried and sieved using a $2 \mathrm{~mm}$ sieve prior to analysis. Scanning of soil samples was conducted using atomic absorption spectrometer to get soil reflectance values. The spectrometer was then used to extract reflectance values for each of the elements $(\mathrm{N}, \mathrm{P}, \mathrm{K}, \mathrm{Ph}, \mathrm{C})$ which were then taken for wet chemistry analysis. The contents of nutrient elements were used to correlate bands with actual mineral values. These were then used to estimate for the rest of the samples.

\section{Data analysis}

\section{Image classification}

Maximum Likelihood (ML) supervised classifier, one of the most commonly used methods for classifying remotely-sensed data (Strahler, 1980; Conese and Maselli, 1992; Foody et al., 1992; Wei and Mendel, 2000; Bruzzone and Prieto, 2001; Seto and Liu, 2003) was used to delineate the fragmented and intact forest classes. Based on the developed class signatures, a thematic map was produced and smoothed using the majority filter rule. A total of 82 ground truth points were used to generate a confusion matrix to determine the overall (OA), producer's (PA) and user's (UA) accuracies. 


\section{Modelling fragmentation}

Fragmentation in the Uluguru forest block was modelled using Fragstats metrics. Fragstats is a spatial statistics program useful in computing metrics at patch, class and landscape level (McGarigal and Marks, 1995). It is distinct in nature and has the capacity to estimate landscape behavior characteristics (Millington et al., 2003; Saikia et al., 2013). In this study, the classified RapidEye image was converted to ASCII format and analyzed to get different patch parameters. According to Didham (2001) patch metrics are valuable in characterizing fragmentation, consequently, patch metrics were combined with species data for further analysis.

\section{Statistical analyses}

Poisson regression was used to investigate significant differences in species abundance between fragmented and intact habitats. Student t-tests were used to determine differences between intact and fragmented habitats in relation to elevation, patch area and soil nitrogen content. Relationships between patch area and soil nitrogen content and patch area and elevation were investigated. Elevation and patch area are considered important estimators of habitat heterogeneity and fragmenting landscape respectively (Kerr et al., 2001).

\section{Calculation of species diversity}

Species diversity was calculated from field measurements using the Shannon-Weaver diversity index. The analyses were performed in $\mathrm{R}$ version 2.10.0 ( $\mathrm{R}$ Development Core Team, 2009) for field data collected from the Ulugurus. Shannon-Weaver diversity index is a measure of the diversity index of a species community and combines richness and evenness. It is a non-parametric statistical parameter based on the proportion of species relative (qi) to the total number of species (Q) (Chao and Shen, 2003). Species diversity was calculated, taking into account the number of species per family present in the forest ecosystem and was computed using the equation:

$$
H^{\prime}=-\sum_{i=1}^{S}\left(\frac{q i}{Q}\right) \log \left(\frac{q i}{Q}\right)
$$

Where: $\mathrm{H}^{\prime}$ is the Shannon-Weaver diversity index, qi is the fraction of individuals belonging to the i species, Q is the total number of individual species in the sample, and $S$ is the species richness (Shannon and Weaver, 1963). Species diversity was then categorized in two groups: low and high values, which were converted to readable text file format with geographic co-ordinates for processing in GARP.

\section{Species niche modelling Using GARP Algorithm}

GARP is a genetic algorithm that creates ecological niche models for species. The models describe environmental conditions under which the species are able to maintain populations. For input, GARP uses a set of point localities where the species is known to occur and a set of geographic layers representing the environmental parameters that might limit the species' capabilities to survive. The algorithm applies the best subsets 
procedure using the new open modeller implementation in each GARP run. Remote sensing variables were extracted based on the high resolution RapidEye satellite data and measurements linked to species habitat requirements. Kriging was applied to the rest of variables i.e. N, P, K, C then converted into ASCII format, a format accepted by GARP model. An Aster Digital Elevation Model (DEM) was also converted to the ASCII format. This was used to establish relationships between species diversity and other environmental variables including $\mathrm{N}, \mathrm{P}, \mathrm{K}, \mathrm{C}, \mathrm{pH}$, DEM, and RapidEye satellite data. All variables used in the model were screened to test for highly correlated variables using the Pearson correlation tests. With values $r<0.7$ shows no correlation (Olson et al., 2014). A Pearson correlation test was employed to assess relationships between Shannon wiener index and each of the environmental parameters.

\section{Jack Knife Tests}

Jack Knife tests were used to assess the importance of the variables used in running the model (Saatchi et al., 2008). This test is in-built in the GARP model which is important in testing the significance of each of the environmental variables used. It generates a model that estimates the accuracy for the entire layer set. Then for each layer, a new model is generated without that particular layer and the accuracy determined. All models were trained with similar points randomly selected from given occurrence points, and the accuracy calculated with the rest of the test points using $75 \%$ of the data. The area under curve (AUC) was used in assessing the level of significance of the curve. According to Bell, (1999) values less than 0.5 are regarded as uninformative, between 0.7 and 0.8 as acceptable and above 0.8 signify a good fit.

\section{Further model validation}

The model was further validated using the partial receiver operating curve (ROC). We integrated species presence data and area dependent suitability file generated as an ASCII file in GARP. This was then converted as a grid format and points extracted in ArcGIS 10.2. The two data sets were run in partial roc setup and run with a proportion of points set at 50 .

\section{Results}

Figure 2 shows a thematic map obtained using ML classifier. An overall classification accuracy of $84 \%$ was obtained with individual accuracies for both classes more than $80 \%$, except the producer's accuracy for intact forest (Table 1). The classifications show that North Uluguru has relatively more intact forest than south Uluguru (Figure 2).

Table 1. Classification accuracy measures for the thematic map

\begin{tabular}{|l|c|c|c|c|c|}
\hline Class name & Correctly classified & Misclassified & Total & PA (\%) & UA (\%) \\
\hline $\begin{array}{l}\text { Fragmented } \\
\text { forest }\end{array}$ & 54 & 2 & 56 & 96.43 & 83.08 \\
\hline Intact forest & 15 & 11 & 26 & 57.69 & 100.00 \\
\hline OA (\%) & 84.15 & & & \\
\hline
\end{tabular}




\section{Abundance of tree species}

A total of 1,394 trees, comprising 55 different species categories were found in Uluguru forest block. The species discovery curve (Figure 3) shows relations between discovered and sampled species.

The Syzygium cordatum Hochst.ex C.Krauss was the most dominant tree species, constituting $18 \%$ of the total trees measured (Figure 4 ). On average, elevation for Uluguru forest was $1,951.63 \mathrm{~m}$. There was no significant difference $(p \geq 0.05)$ in elevation status between intact $(1901 \mathrm{~m})$ and fragmented $(2056 \mathrm{~m})$ habitats in Uluguru forest $(\mathrm{t}=-1.515, p=0.134)$.

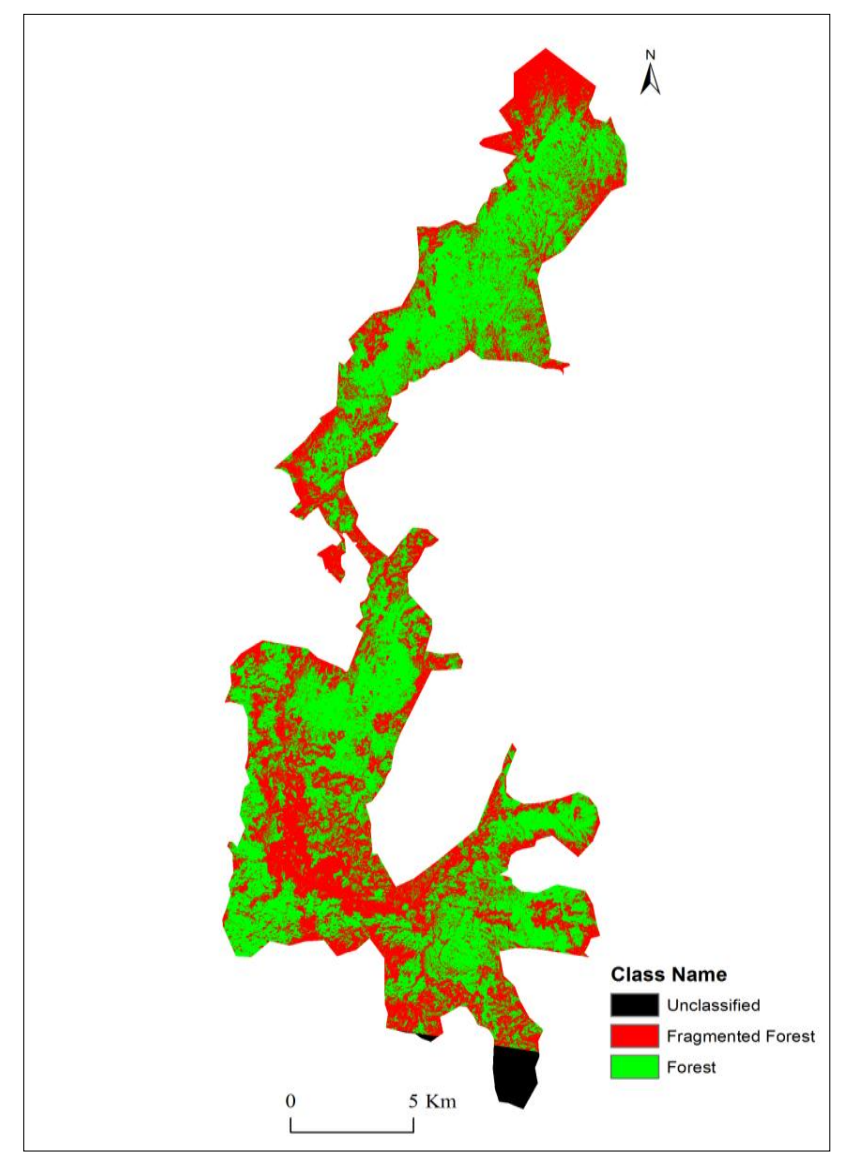

Figure 2. Fragmented and intact forests in the study area

\section{Impacts of forest fragmentation on patch area and soil health}

The mean patch area was $41,108 \mathrm{~m}^{2}$, which varied significantly $(\mathrm{t}=2.781, p=0.007)$ between intact $\left(52,665 \mathrm{~m}^{2}\right)$ and fragmented $\left(17,106 \mathrm{~m}^{2}\right)$ habitats. There was no significant difference in nitrogen content between intact and fragmented forests $(p=0.242)$. The average soil nitrogen level for Uluguru was $0.50 \mathrm{mg} / \mathrm{g}$, which was relatively similar in intact $(0.53)$ and fragmented $(0.45)$ habitats.

\section{Impacts of forest fragmentation on species abundance and soil health}

Individual species responded differently to changes in patch area, habitat status and soil nitrogen content (Table 2). The abundance of some species increased (a positive 
estimate value) with an increase in patch area while others decreased (a negative estimate value). For instance, the abundance of Syzygium cordatum Hochst.ex C.Krauss $(p<0.001)$, Allanblackia uluguruensis Engl $(p<0.001)$, and Maesa lanceolata Forssk $(p<0.001)$ increased significantly with an increase in patch area. While the abundance of Mytenus undata Thunb ( $p<0.001$ ), Zenkerella capparidacea (Taub.) J.Leon ( $p<$ $0.001)$ and Oxyanthus specious DC. $(p=0.023)$ decreased significantly. Some tree species were more abundant in intact areas than in fragmented areas, after adjusting for the effect of patch area and nitrogen level and vice versa. Syzygium cordatum Hochst.ex C.Krauss ( $p<0.0001)$, Allanblackia uluguruensis Engl $(p=0.003)$, and Maesa lanceolata Forssk $(p=0.047)$ were more abundant in fragmented habitats, while Mytenus undata Thunb $(p<0.001)$, Zenkerella capparidacea (Taub.) J.Leon ( $p<$ $0.001)$, and Oxyanthus specious DC. $(p=0.008)$ were more abundant in intact areas (Table 2). Results also showed that soil nitrogen content varied with a change in habitat status which also influenced the abundance of species in both fragmented and nonfragmented areas. For instance, adjusting the effect of patch area and habitat status, the abundance of species intensified in some dominant tree species, while others decreased with higher levels of nitrogen (Table 2). Species populations also correlated inversely with changes in nitrogen. For instance, the abundance of Zenkerella capparidacea (Taub.) J.Leon $(\mathrm{p}<0.001)$ and Psychotria goetzei (K.Schum.) E.M.A was lowest under low nitrogen conditions $(p=0.049)$.

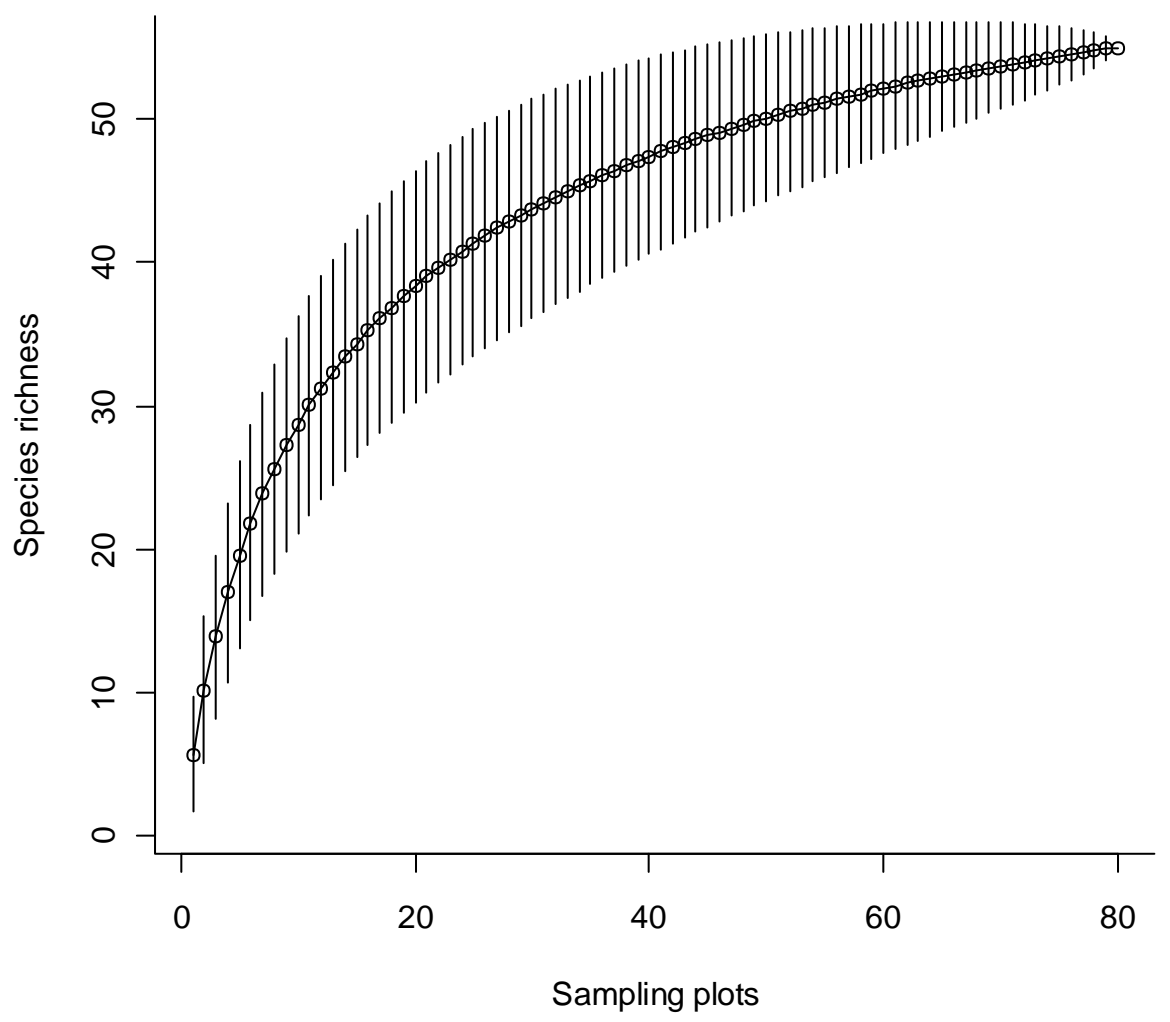

Figure 3. Species discovery curve (accumulation curve)

\section{GARP model AUC KAPPA results}

The model was run producing a high total area under curve (AUC) accuracy of 0.89 , which signifies a good fit of the model. In further validation of the model in Partial Roc, 
a value of 1.27 was generated. This is within the 1-1.5 range which is an indicator of a very good model prediction. The Jackknife test results generated an overall internal test accuracy of $72.31 \%$ and a Roc score of 0.89 while the external test accuracy was $81.82 \%$ and a Roc score of 0.94 . The total area under curve (AUC) was 0.89 .

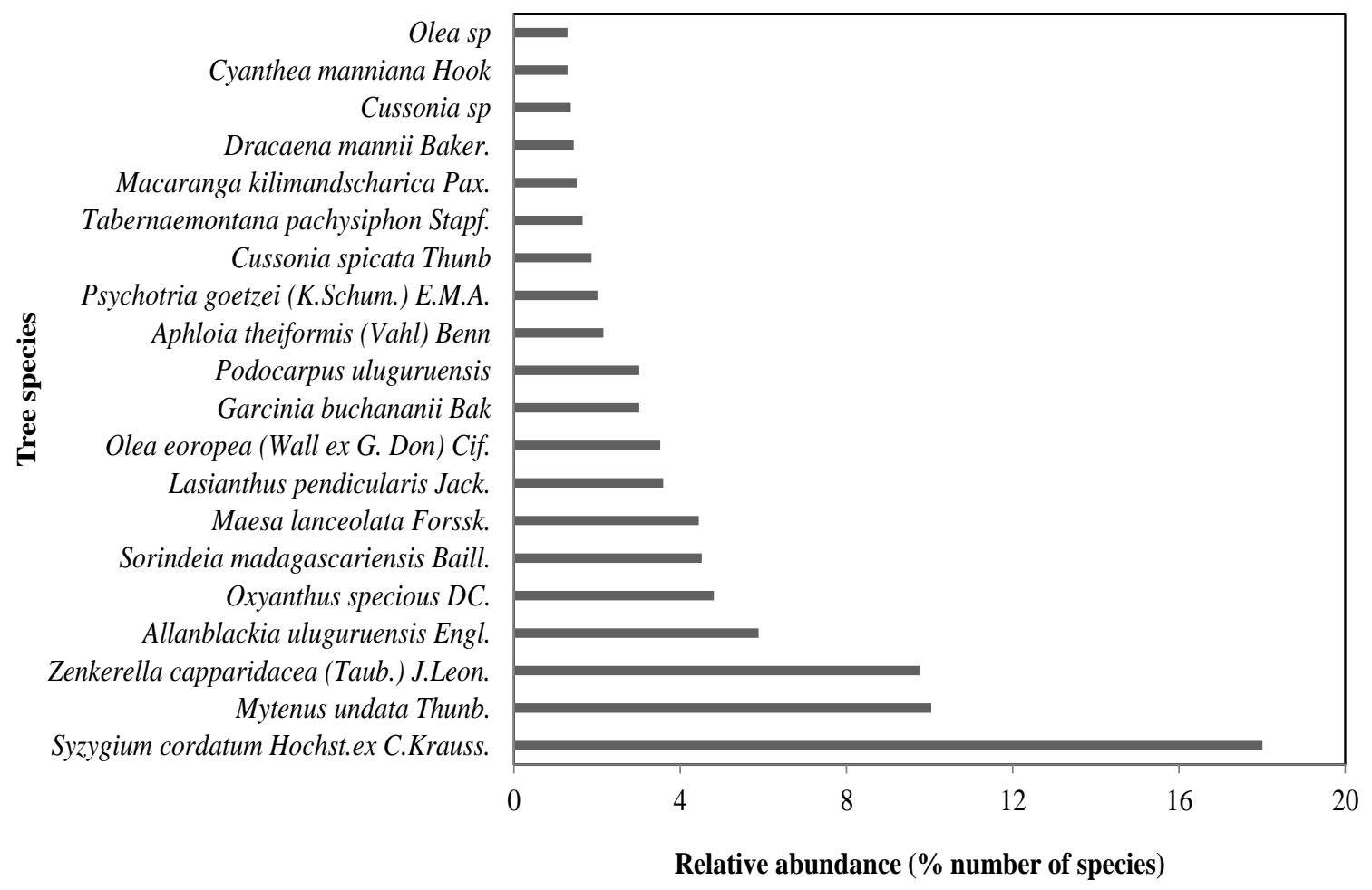

Figure 4. Rank-abundance curve for dominant tree species

\section{Species diversity}

A total of 1,394 trees, comprising 55 species, were recorded. There was higher species diversity in Uluguru South than Uluguru North (p-value: 6.026e-05). No variables used in the model were highly correlated i.e. $r<0.7$. Pearson correlations between the Shannon wiener index and each of the environmental variables showed a positive correlation between most of the variables $(C: r=0.26, N: r=0.25, P: r=0.22$, DEM: $r=0.37$ ) except $\mathrm{K}: \mathrm{r}=-0.25$. DEM, $\mathrm{C}, \mathrm{N}, \mathrm{Ph}, \mathrm{P}$ had a significant influence on the model. The DEM had the greatest effect on the model.

High species diversity was dominant in intact areas located in the central region of the Uluguru forest (Figure 5A) while low species diversity was widespread in fragmented areas (Figure 5B). Areas characterized by zero values are not well placed to support high species diversity due to the extent of fragmentation beyond the threshold.

\section{Discussion}

This study provides important findings on effects of fragmentation on species abundance in the Uluguru forest area based on field measurements and remotely sensed data. The relatively high overall accuracy (see Table 1) of mapping fragmented and intact forest in the study area provided an important basis for investigating the impact of 
Table 2. Poisson regression model results for the relationship between abundance of tree species and mean patch area (ha), habitat status and soil nitrogen content for the dominant species in Uluguru forest area

\begin{tabular}{|c|c|c|c|c|c|c|c|}
\hline \multirow{21}{*}{ 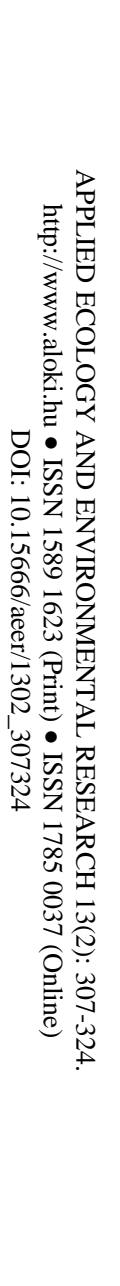 } & \multirow{2}{*}{ Species } & \multicolumn{2}{|c|}{ Patch area (ha) } & \multicolumn{2}{|c|}{ Habitat Status } & \multicolumn{2}{|c|}{ Nitrogen level (g kg-1) } \\
\hline & & Estimate \pm se & $P$ value & Estimate \pm se & $P$ value & Estimate \pm se & $P$ value \\
\hline & Syzygium cordatum Hochst.ex C.Krauss. & $0.00001 \pm 0.000001$ & $<0.001$ & $1.17 \pm 0.14$ & $<0.001$ & $0.58 \pm 0.16$ & $<0.001$ \\
\hline & Mytenus undata Thunb. & $-0.00004 \pm 0.000007$ & $<0.001$ & $-2.40 \pm 0.33$ & $<0.001$ & $0.76 \pm 0.33$ & 0.020 \\
\hline & Zenkerella capparidacea (Taub.) J.Leon. & $-0.00002 \pm 0.000006$ & $<0.001$ & $-0.81 \pm 0.21$ & $<0.001$ & $-1.91 \pm 0.53$ & $<0.001$ \\
\hline & Allanblackia uluguruensis Engl. & $0.00001 \pm 0.000002$ & $<0.001$ & $0.75 \pm 0.25$ & 0.003 & $0.71 \pm 0.27$ & 0.008 \\
\hline & Oxyanthus specious DC. & $-0.00003 \pm 0.000015$ & 0.023 & $-2.74 \pm 1.03$ & 0.008 & $0.28 \pm 0.95$ & 0.769 \\
\hline & Sorindeia madagascariensis Baill. & $-0.00004 \pm 0.000013$ & 0.001 & $-0.92 \pm 0.30$ & 0.002 & $0.74 \pm 0.43$ & 0.086 \\
\hline & Maesa lanceolata Forssk. & $0.00001 \pm 0.000003$ & $<0.001$ & $0.61 \pm 0.31$ & 0.047 & $0.79 \pm 0.29$ & 0.007 \\
\hline & Lasianthus pendicularis Jack. & $-0.00004 \pm 0.000013$ & $<0.001$ & $-1.89 \pm 0.48$ & $<0.001$ & $-0.39 \pm 0.69$ & 0.578 \\
\hline & Olea eoropea (Wall ex G. Don) Cif. & $0.00001 \pm 0.000003$ & 0.008 & $1.22 \pm 0.31$ & $<0.001$ & $0.003 \pm 0.44$ & 0.995 \\
\hline & Garcinia buchananii Bak & $0.00001 \pm 0.000003$ & $<0.001$ & $2.14 \pm 0.37$ & $<0.001$ & $1.16 \pm 0.36$ & 0.001 \\
\hline & Podocarpus uluguruensis & $0.00004 \pm 0.000003$ & 0.244 & $1.84 \pm 0.37$ & $<0.001$ & $0.38 \pm 0.43$ & 0.382 \\
\hline & Aphloia theiformis (Vahl) Benn & $0.00011 \pm 0.000003$ & 0.002 & $0.43 \pm 0.41$ & 0.301 & $-0.29 \pm 0.61$ & 0.634 \\
\hline & Psychotria goetzei (K.Schum.) E.M.A. & $-0.00001 \pm 0.000007$ & 0.17 & $0.35 \pm 0.38$ & 0.362 & $-2.08 \pm 1.06$ & 0.049 \\
\hline & Cussonia spicata Thunb & $0.00003 \pm 0.000006$ & $<0.001$ & $1.53 \pm 0.53$ & 0.004 & $2.08 \pm 0.36$ & $<0.001$ \\
\hline & Tabernaemontana pachysiphon Stapf. & $-0.00001 \pm 0.000011$ & 0.235 & $-1.91 \pm 0.74$ & 0.010 & $-4.48 \pm 1.91$ & 0.019 \\
\hline & Macaranga kilimandscharica Pax. & $0.000018 \pm 0.00001$ & 0.066 & $-2.32 \pm 0.76$ & 0.002 & $-19.21 \pm 3.94$ & $<0.001$ \\
\hline & Dracaena mannii Baker. & $0.00002 \pm 0.000006$ & 0.003 & $-0.002 \pm 0.69$ & 0.998 & $-1.02 \pm 1.12$ & 0.363 \\
\hline & Cussonia sp & $-0.00004 \pm 0.000033$ & 0.217 & $0.264 \pm 0.46$ & 0.570 & $-1.562 \pm 1.19$ & 0.190 \\
\hline & $\begin{array}{l}\text { Cyanthea manniana Hook } \\
\text { Olea sp }\end{array}$ & $\begin{array}{r}0.00002 \pm 0.000011 \\
-0.000003 \pm 0.00002\end{array}$ & $\begin{array}{l}0.840 \\
0.170\end{array}$ & $\begin{array}{l}-1.815 \pm 0.76 \\
-1.667 \pm 0.75\end{array}$ & $\begin{array}{l}0.017 \\
0.027\end{array}$ & $\begin{array}{r}-10.395 \pm 3.07 \\
-2.724 \pm 1.77\end{array}$ & $\begin{array}{l}0.001 \\
0.123\end{array}$ \\
\hline
\end{tabular}


habitat fragmentation on species abundance and diversity. Results show that fragmentation is intensive on the outskirts of the Uluguru forest (see Figure 3). The results are discussed in the context of how fragmentation affects species abundance and diversity and related conservation implications.

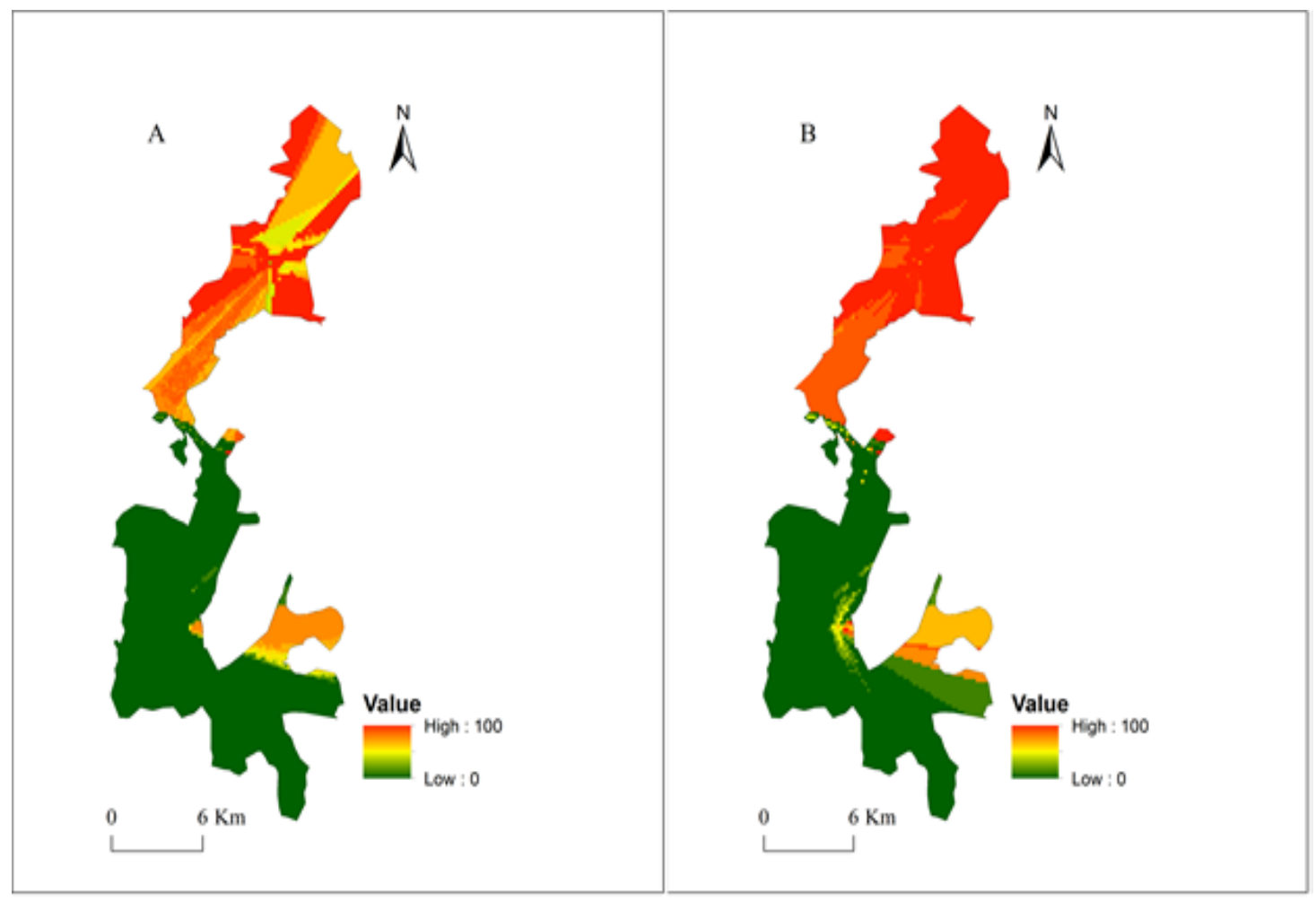

Figure 5. Probability for high (A) and low (B) species diversity

\section{Fragmentation impacts on species abundance under dynamic soil health conditions}

Individual species responded differently to changes in patch area. Species abundance of some tree species declined with an increase in patch area, while others decreased. For instance, the abundance of Syzygium cordatum Hochst.ex C.Krauss, Allanblackia uluguruensis Engl, and Maesa lanceolata Forssk increased in disturbed areas compared to intact areas. These species prefer abundant light associated with forest fragmentation (Cunningham, 2001). Other species such as Mytenus undata Thunb, Zenkerella capparidacea (Taub.) J.Leon, and Oxyanthus specious DC were more abundant in intact habitats than fragmented areas. This suggested that such species are prone to forest disturbance and therefore need to be prioritized for conservation.

More tree species were scattered with a low similarity along study plots with frequent occurrence of tree stumps where field assessments were conducted. A negative correlation was established on the abundance of species like Oxyanthus specious which decreased with an increase in patch area while Mytenus undata Thunb, Zenkerella capparidacea (Taub.) J.Leon and Oxyanthus specious DC significantly decreased. A decrease in patch area provides an indication that a habitat undergoing fragmentation (McGarigal and Cushman, 2002; Wu et al., 2002; McGarigal, 2006). It opens up other avenues for increasing edge effects caused by human settlements and tree logging which in turn interferes with the habitat configuration of species through increased 
exposure to soil erosion and drying up of soil moisture and erosion of nutrients (Gould, 2000; Burgess et al., 2007b). The findings are consistent with the study by Echeverría et al., (2007) which established fragmentation effects on vegetation species in southern Chile. Fragmentation also escalates the degree of patchiness of a habitat which has an effect on an ecosystem's configuration and biophysical processes (Lovett et al., 2006; Maeda et al., 2010).

Furthermore, species abundance varied significantly, which could be attributed to changes in soil in both intact and fragmented areas. The threat posed to soil is an aspect that suggests progressive fragmentation could intensify the susceptibility of important ecosystem soil elements to attrition. The level of soil nitrogen in fragmented areas was less compared to that in less fragmented areas. Typically, a fragmenting habitat is characterized by low nitrogen content (Billings and Gaydess, 2008). Changing land use play a role as they influence soil health properties (Davidson et al., 2004; Amazonas et al., 2011). Frequent disturbances opens up intact habitats to soil erosion, loss of organic matter and other necessary elements useful for vegetation growth (Guggenberger et al., 1994; Foley et al., 2005).

\section{Impacts of fragmentation on species diversity}

Applying remote sensing variables such as the fragmentation index map, DEM and edaphic factors were useful in species diversity prediction. In this study, species diversity was better predicted using customized variables with an AUC of 0.86 when the model was tested using partial ROC value of 1.27. High species diversity was associated with less fragmented land use type, high terrain and good soil conditions not exposed to harsh environmental conditions and heat. This was reflected in jackknife analysis that showed variables with the highest effect on the model. The soil variables and DEM influenced the model by $72 \%$. The GARP model result produced an AUC of 0.89 . GARP model has the advantage of predicting entire species diversity distribution as opposed to Maxent which only predicts the distribution of input occurrence data (Townsend Peterson et al., 2007). It has also been successfully used in other studies targeting regional or local scale predictions (Woodward and Beerling, 1997).

High species diversity was evident in intact non-fragmented areas. Areas characterized by zero values were not well placed to support high species diversity due to the wide extent of fragmentation. Low species diversity was prevalent in fragmented areas associated with low values of nitrogen, carbon, potassium and phosphorus in the Uluguru North. This is attributed to increased anthropogenic activities in the area (Shirima et al., 2011). This further confirms a similar study finding which associated high species diversity with intact areas attributed to less human disturbances (Rashid et al., 2013). Other related studies established less species in sites exposed to predation (Olson et al., 2014).

Based on the GARP algorithm, generally, Uluguru forest block has a high potential for high species diversity. It is possible to restore the entire region into a high species diversity site despite the increasing rate of external perturbations from anthropogenic activities. Ecologists support the argument that disturbed ecosystems with a high diversity response have a better chance of restoration after disturbance, as opposed to ecosystems with low diversity (Folke et al., 2004). If the habitat is conserved, most likely endemic and vulnerable species will be protected from more exposure to harsh environmental conditions (Armenteras et al., 2003; Burgess et al., 2007b; Buermann et 
al., 2008; Burgess et al., 2013) and other ecological risks (Folke et al., 2004). This could significantly contribute to low endemism and extinction rates (Şekercioğlu et al., 2004).

\section{Conservation Implications}

Anthropogenic activity affects species occurrences and survival rates (Tilman and Lehman, 2001; Pineda and Halffter, 2004; MacDougall et al., 2013). The site portrays a strong probability of high species diversity with a great ecological resilience capacity. Conservation organizations and decision makers need to encourage good conservation practices that will counteract loss of vegetation in the area. One of the challenges facing management of fragile ecosystems is development of socio-ecological resilience that can in principle contain dynamic landscapes (Daily, 2000; Fischer et al., 2004; Folke et al., 2004; Foley et al., 2005). The need for example, to support development of appropriate scenarios with the capacity to support sustainable livelihoods while conserving the habitat need to be strengthened. The other factor which may account for species losses is poor institutional frameworks. A previous finding indicated that institutions, which are lacking in Uluguru region, play a critical role in fostering community response to sustainable use of natural resources. Based on field observations, most communities are not motivated into sustainable forest conservation activities. Therefore, pursuing sustainable forest management while integrating local institutional frameworks can be a sound and a better step in strengthening governance frameworks in biodiversity conservation (Lopa et al., 2012).

Based on findings of this study, habitat fragmentation can be considered to be a major threat to conservation in the region. Findings showed that in areas of high terrain, the intensity of fragmentation was relatively high. This could be associated with rich biodiversity resources in high terrain areas in the Ulugurus (Swetnam et al., 2011). Though the abundance of species varied with changes in habitat status, it emerged that most dominant species were affected. It will be appropriate if decision makers and conservation biologists could support conservation efforts in the region as it still remains susceptible to increased endemism and extinction. This is due to the increasing population leading to clearing of the Uluguru slopes in search of greener pastures (Burgess et al., 2007b). Furthermore, expansion of the urban set-ups at Morogoro town and surrounding smaller towns facilitate easy accessibility to markets in Morogoro region which drive forest loss in Uluguru.

Generally, the Eastern Arc mountains have a very conducive and reliable climate (Mumbi et al., 2008). This is useful in establishment of agricultural systems and therefore attractive to subsistence farmers in Tanzania (Burgess et al., 2007a). Intensification of agricultural systems and settlements presents a key threat to species abundance and survival in the Ulugurus (Burgess et al., 2007b). Although population density is projected to intensify in the coming decades, the worst case scenario is expected (Fjeldså, 1999; Hall et al., 2009; Swetnam et al., 2011). Most likely species existence might become irreplaceable in the long-term if the trend persists (Rondinini et al., 2006).

\section{Conclusions}

The present study has yielded valuable insights regarding the ecological importance of forest fragmentation on the abundance and diversity of fundamental species in Tanzania. Overall, fragmentation presents a great challenge to species abundance and 
diversity in the Uluguru forest block. We make important observations from the study: 1) Fragmentation is having an impact on species abundance under changing soil conditions, and 2) The use of Genetic Algorithm for Rule-Set Prediction (GARP model) and remote sensing variables are useful in discerning impacts of fragmentation on species diversity in the Uluguru forest block. Our study results suggest the need to accord priority to habitat restoration and conservation efforts in the long term plans for the fragmenting habitat.

Acknowledgements. RapidEye satellite imagery was provided by DLR-German Aerospace Centre. Financial support was provided by UNESCO L'Oreal Foundation for Women in Scientific Research and the IDRC Graduate Research Grant, Ontario, Canada. H. Seki and G. Bulenga from Sokoine University of Agriculture, forestry department and the staff of Wami/Ruvu Basin office in Tanzania supported fieldwork implementation. The contribution by G. Mosomtai is appreciated. Sincere appreciation is extended to government forestry departments and leaders in Morogoro region for their support and cooperation at all stages of fieldwork.

\section{REFERENCES}

[1] Achard, F., Eva, H.D., Stibig, H.-J., Mayaux, P., Gallego, J., Richards, T., Malingreau, J.P. (2002): Determination of Deforestation Rates of the World's Humid Tropical Forests.Science 297:999-1002.

[2] Adams, M., Cooper, J., Collar, N. (2003): Extinct and endangered (EandE') birds: a proposed list for collection catalogues. - Bulletin-British Ornithologists Club 123:338354.

[3] Amazonas, N.T., Martinelli, L.A., Piccolo, M.d.C., Rodrigues, R.R. (2011): Nitrogen dynamics during ecosystem development in tropical forest restoration. - Forest Ecology and Management 262:1551-1557.

[4] Araújo, M.B., Luoto, M. (2007): The importance of biotic interactions for modelling species distributions under climate change. - Global Ecology and Biogeography 16:743753.

[5] Armenteras, D., Gast, F., Villareal, H.(2003): Andean forest fragmentation and the representativeness of protected natural areas in the eastern Andes, Colombia. - Biological Conservation 113:245-256.

[6] Benítez-Malvido, J., Martínez-Ramos, M.(2003): Impact of forest fragmentation on understory plant species richness in Amazonia. - Conservation Biology 17:389-400.

[7] Billings, S.A., Gaydess, E.A. (2008): Soil nitrogen and carbon dynamics in a fragmented landscape experiencing forest succession. -Landscape Ecol 23:581-593.

[8] Bjorndalen, J.E. (1992): Tanzania's vanishing rain forests-assessment of nature conservation values, biodiversity and. - Biotic Diversity in Agroecosystems, 313.

[9] Bogich, T.L., Barker, G.M., Mahlfeld, K., Climo, F., Green, R., Balmford, A. (2012): Fragmentation, grazing and the species-area relationship. -Ecography 35:224-231.

[10] Bruzzone, L., Prieto, D.F. (2001): Unsupervised retraining of a maximum likelihood classifier for the analysis of multitemporal remote sensing images. Geoscience and Remote Sensing, IEEE Transactions on 39:456-460.

[11] Buermann, W., Saatchi, S., Smith, T.B., Zutta, B.R., Chaves, J.A., Milá, B., Graham, C.H. (2008): Predicting species distributions across the Amazonian and Andean regions using remote sensing data. - Journal of Biogeography 35:1160-1176.

[12] Burgess, N., Doggart, N., Lovett, J.C. (2002): The Uluguru Mountains of eastern Tanzania: the effect of forest loss on biodiversity. - Oryx 36:140-152. 
[13] Burgess, N., Romdal, T.S., Rahner, M. (2001): Forest loss on the Ulugurus, Tanzania and the status of the Uluguru Bush Shrike Malconotus alius. - Bulletin of the African Bird Club 8:89-90.

[14] Burgess, N.D., Balmford, A., Cordeiro, N.J., Fjeldså, J., Küper, W., Rahbek, C., Sanderson, E.W., Scharlemann, J.P.W., Sommer, J.H., Williams, P.H. (2007a): Correlations among species distributions, human density and human infrastructure across the high biodiversity tropical mountains of Africa. - Biological Conservation 134:164177.

[15] Burgess, N.D., Butynski, T.M., Cordeiro, N.J., Doggart, N.H., Fjeldså, J., Howell, K.M., Kilahama, F.B., Loader, S.P., Lovett, J.C., Mbilinyi, B., Menegon, M., Moyer, D.C., Nashanda, E., Perkin, A., Rovero, F., Stanley, W.T., Stuart, S.N. (2007b): The biological importance of the Eastern Arc Mountains of Tanzania and Kenya. - Biological Conservation 134:209-231.

[16] Burgess, N.D., Fjeldså, J., Botterweg, R. (1998): Faunal Importance of the Eastern Arc Mountains of Kenya and Tanzania. - Journal of East African Natural History 87:37-58.

[17] Burgess, N.D., Mwakalila, S., Munishi, P., Pfeifer, M., Willcock, S., Shirima, D., Hamidu, S., Bulenga, G.B., Rubens, J., Machano, H., Marchant, R. (2013): REDD herrings or REDD menace: Response to Beymer-Farris and Bassett. - Global Environmental Change 23:1349-1354.

[18] Carlson, K., Asner, G., Hughes, R.F., Ostertag, R., Martin, R. (2007): Hyperspectral Remote Sensing of Canopy Biodiversity in Hawaiian Lowland Rainforests. - Ecosystems 10:536-549.

[19] Chao, A., Shen, T.-J. (2003): Nonparametric estimation of Shannon's index of diversity when there are unseen species in sample. - Environmental and Ecological Statistics 10: 429-443.

[20] Conese, C., Maselli, F. (1992): Use of error matrices to improve area estimates with maximum likelihood classification procedures. - Remote sensing of Environment 40: $113-124$.

[21] Cunningham, A. (2001): Applied Ethnobotany:" People, Wild Plant Use and Conservation". Earthscan.

[22] Daily, G.C. (2000): Management objectives for the protection of ecosystem services. Environmental Science and Policy 3:333-339.

[23] Davidson, E.A., Reis de Carvalho, C.J., Vieira, I.C., Figueiredo, R.d.O., Moutinho, P., Yoko Ishida, F., Primo dos Santos, M.T., Benito Guerrero, J., Kalif, K., Tuma Sabá, R. (2004): Nitrogen and phosphorus limitation of biomass growth in a tropical secondary forest. - Ecological Applications 14:150-163.

[24] Debinski, D.M., Kindscher, K., Jakubauskas, M.E. (1999): A remote sensing and GISbased model of habitats and biodiversity in the Greater Yellowstone Ecosystem. International Journal of Remote Sensing 20:3281-3291.

[25] DeFries, R.S., Houghton, R.A., Hansen, M.C., Field, C.B., Skole, D., Townshend, J. (2002): Carbon emissions from tropical deforestation and regrowth based on satellite observations for the 1980s and 1990s. - Proceedings of the National Academy of Sciences 99:14256-14261.

[26] Didham, R.K. (2001): Ecological Consequences of Habitat Fragmentation. eLS. John Wiley and Sons, Ltd.

[27] Echeverría, C., Newton, A.C., Lara, A., Benayas, J.M.R., Coomes, D.A. (2007): Impacts of forest fragmentation on species composition and forest structure in the temperate landscape of southern Chile. - Global Ecology and Biogeography 16:426-439.

[28] Erik Bjørndalen, J. (1992): Tanzania's vanishing rain forests - assessment of nature conservation values, biodiversity and importance for water catchment. - Agriculture, Ecosystems and Environment 40:313-334.

[29] Fageria, N.K. (2010): The use of nutrients in crop plants. - CRC Press. 
[30] Fahrig, L., (2003): Effects of habitat fragmentation on biodiversity. - Annual review of ecology, evolution, and systematics 34:487-515.

[31] Fischer, J., B. Lindenmayer, D. (2006): Beyond fragmentation: the continuum model for fauna research and conservation in human-modified landscapes. - Oikos 112:473-480.

[32] Fischer, J., Lindenmayer, D.B., Fazey, I. (2004): Appreciating Ecological Complexity: Habitat Contours as a Conceptual Landscape Model Valorando la Complejidad Ecológica: Contornos de Hábitat como un Modelo Conceptual del Paisaje. Conservation Biology 18:1245-1253.

[33] Fjeldså, J. (1999): The impact of human forest disturbance on the endemic avifauna of the Udzungwa Mountains, Tanzania. - Bird Conservation International 9:47-62.

[34] Foley, J.A., DeFries, R., Asner, G.P., Barford, C., Bonan, G., Carpenter, S.R., Chapin, F.S., Coe, M.T., Daily, G.C., Gibbs, H.K., Helkowski, J.H., Holloway, T., Howard, E.A., Kucharik, C.J., Monfreda, C., Patz, J.A., Prentice, I.C., Ramankutty, N., Snyder, P.K. (2005): Global Consequences of Land Use. - Science 309:570-574.

[35] Folke, C., Carpenter, S., Walker, B., Scheffer, M., Elmqvist, T., Gunderson, L., Holling, C.S. (2004): Regime shifts, resilience, and biodiversity in ecosystem management. Annual Review of Ecology, Evolution, and Systematics 35:557-581.

[36] Foody, G.M., Campbell, N., Trodd, N., Wood, T. (1992): Derivation and applications of probabilistic measures of class membership from the maximum-likelihood classification. - Photogrammetric Engineering and Remote Sensing 58:1335-1341.

[37] Fuchs, J., Fjeldså, J., Pasquet, E. (2005): The use of mitochondrial and nuclear sequence data in assessing the taxonomic status of the endangered Uluguru Bush Shrike Malaconotus alius. - Ibis 147:717-724.

[38] Gould, W. (2000): Remote sensing of vegetation, plant species richness, and regional biodiversity hotspots. - Ecological Applications 10:1861-1870.

[39] Griffiths, G.H., Lee, J. (2000): Landscape pattern and species richness; regional scale analysis from remote sensing. - International Journal of Remote Sensing 21:2685-2704.

[40] Guggenberger, G., Christensen, B.T., Zech, W. (1994): Land-use effects on the composition of organic matter in particle-size separates of soil: I. Lignin and carbohydrate signature. - European Journal of Soil Science 45:449-458.

[41] Hall, J., Burgess, N.D., Lovett, J., Mbilinyi, B., Gereau, R.E. (2009): Conservation implications of deforestation across an elevational gradient in the Eastern Arc Mountains, Tanzania. - Biological Conservation 142:2510-2521.

[42] Helm, A., Hanski, I., Pärtel, M. (2006): Slow response of plant species richness to habitat loss and fragmentation. - Ecology Letters 9:72-77.

[43] Hobbs, N.T., Galvin, K.A., Stokes, C.J., Lackett, J.M., Ash, A.J., Boone, R.B., Reid, R.S., Thornton, P.K. (2008): Fragmentation of rangelands: Implications for humans, animals, and landscapes. - Global Environmental Change 18:776-785.

[44] Kerr, J.T., Southwood, T.R.E., Cihlar, J. (2001): Remotely sensed habitat diversity predicts butterfly species richness and community similarity in Canada. - Proceedings of the National Academy of Sciences 98:11365-11370.

[45] Laurance, W. (2007): Ecosystem decay of Amazonian forest fragments: implications for conservation. - In: Tscharntke, T., Leuschner, C., Zeller, M., Guhardja, E., Bidin, A. (Eds.) Stability of Tropical Rainforest Margins., Springer Berlin Heidelberg, pp. 9-35.

[46] Lopa, D., Mwanyoka, I., Jambiya, G., Massoud, T., Harrison, P., Ellis-Jones, M., Blomley, T., Leimona, B., van Noordwijk, M., Burgess, N.D. (2012): Towards operational payments for water ecosystem services in Tanzania: a case study from the Uluguru Mountains. - Oryx 46:34-44.

[47] Lovett, J.C., Marshall, A.R., Carr, J. (2006): Changes in tropical forest vegetation along an altitudinal gradient in the Udzungwa Mountains National Park, Tanzania. - African Journal of Ecology 44:478-490. 
[48] MacDougall, A.S., McCann, K.S., Gellner, G., Turkington, R.(2013): Diversity loss with persistent human disturbance increases vulnerability to ecosystem collapse. - Nature 494: 86-89.

[49] Maeda, E.E., Pellikka, P.K., Siljander, M., Clark, B.J.(2010): Potential impacts of agricultural expansion and climate change on soil erosion in the Eastern Arc Mountains of Kenya. - Geomorphology 123:279-289.

[50] Martínez-Meyer, E., Townsend Peterson, A., Hargrove, W.W. (2004): Ecological niches as stable distributional constraints on mammal species, with implications for Pleistocene extinctions and climate change projections for biodiversity. - Global Ecology and Biogeography 13:305-314.

[51] McGarigal, K. (2006): Landscape Pattern Metrics. Encyclopedia of Environmetrics.John Wiley and Sons, Ltd.

[52] McGarigal, K., Cushman, S.A., (2002): Comparative Evaluation of Experimental Approaches to the study of habitat fragmentation effects. - Ecological Applications 12: 335-345.

[53] Millington, A.C., Velez-Liendo, X.M., Bradley, A.V. (2003): Scale dependence in multitemporal mapping of forest fragmentation in Bolivia: implications for explaining temporal trends in landscape ecology and applications to biodiversity conservation. ISPRS Journal of Photogrammetry and Remote Sensing 57:289-299.

[54] Mumbi, C., Marchant, R., Hooghiemstra, H., Wooller, M. (2008): Late Quaternary vegetation reconstruction from the Eastern Arc Mountains, Tanzania. - Quaternary Research 69:326-341.

[55] Murcia, C. (1995): Edge effects in fragmented forests: implications for conservation. Trends in Ecology and Evolution 10:58-62.

[56] Newmark, W.D. (1998): Forest Area, Fragmentation, and Loss in the Eastern Arc Mountains: Implications For the Conservation of Biological Diversity. - Journal of East African Natural History 87:29-36.

[57] Olson, D.M., Dinerstein, E. (1998): The Global 200: A Representation Approach to Conserving the Earth's Most Biologically Valuable Ecoregions. - Conservation Biology 12:502-515.

[58] Olson, L.E., Sauder, J.D., Albrecht, N.M., Vinkey, R.S., Cushman, S.A., Schwartz, M.K. (2014): Modeling the effects of dispersal and patch size on predicted fisher (Pekania [Martes] pennanti) distribution in the U.S. Rocky Mountains. - Biological Conservation 169:89-98.

[59] Osborne, P.E., Alonso, J.C., Bryant, R.G. (2001): Modelling landscape-scale habitat use using GIS and remote sensing: a case study with great bustards. - Journal of Applied Ecology 38:458-471.

[60] Pearson, R.G., Dawson, T.P. (2003): Predicting the impacts of climate change on the distribution of species: are bioclimate envelope models useful?- Global ecology and biogeography 12:361-371.

[61] Pineda, E., Halffter, G. (2004): Species diversity and habitat fragmentation: frogs in a tropical montane landscape in Mexico. - Biological Conservation 117:499-508.

[62] Rashid, I., Romshoo, S., Vijayalakshmi, T. (2013): Geospatial modelling approach for identifying disturbance regimes and biodiversity rich areas in North Western Himalayas, India. - Biodivers Conserv, 1-30.

[63] Rondinini, C., Chiozza, F., Boitani, L. (2006): High human density in the irreplaceable sites for African vertebrates conservation. - Biological Conservation 133:358-363.

[64] Saatchi, S., Buermann, W., ter Steege, H., Mori, S., Smith, T.B. (2008): Modeling distribution of Amazonian tree species and diversity using remote sensing measurements. - Remote Sensing of Environment 112:2000-2017.

[65] Saikia, A., Hazarika, R., Sahariah, D. (2013): Land-use/land-cover change and fragmentation in the Nameri Tiger Reserve, India. Geografisk Tidsskrift-Danish Journal of Geography 113:1-10. 
[66] Şekercioğlu, Ç.H., Daily, G.C., Ehrlich, P.R. (2004): Ecosystem consequences of bird declines. - Proceedings of the National Academy of Sciences 101:18042-18047.

[67] Seto, K.C., Liu, W. (2003): Comparing ARTMAP neural network with the maximumlikelihood classifier for detecting urban change. - Photogrammetric Engineering and Remote Sensing 69:981-990.

[68] Shirima, D.D., Munishi, P.K.T., Lewis, S.L., Burgess, N.D., Marshall, A.R., Balmford, A., Swetnam, R.D., Zahabu, E.M. (2011): Carbon storage, structure and composition of miombo woodlands in Tanzania's Eastern Arc Mountains. - African Journal of Ecology 49:332-342.

[69] Solomon, D., Lehmann, J., Zech, W.(2000): Land use effects on soil organic matter properties of chromic luvisols in semi-arid northern Tanzania: carbon, nitrogen, lignin and carbohydrates. - Agriculture, Ecosystems and Environment 78:203-213.

[70] Stoms, D.M., Estes, J.E. (1993): A remote sensing research agenda for mapping and monitoring biodiversity. - International Journal of Remote Sensing 14:1839-1860.

[71] Strahler, A.H. (1980): The use of prior probabilities in maximum likelihood classification of remotely sensed data. - Remote Sensing of Environment 10:135-163.

[72] Swetnam, R.D., Fisher, B., Mbilinyi, B.P., Munishi, P.K.T., Willcock, S., Ricketts, T., Mwakalila, S., Balmford, A., Burgess, N.D., Marshall, A.R., Lewis, S.L. (2011): Mapping socio-economic scenarios of land cover change: A GIS method to enable ecosystem service modelling. - Journal of Environmental Management 92:563-574.

[73] Thuiller, W., Lavorel, S., Sykes, M.T., Araújo, M.B. (2006): Using niche-based modelling to assess the impact of climate change on tree functional diversity in Europe. Diversity and Distributions 12:49-60.

[74] Tilman, D., Lehman, C. (2001): Human-caused environmental change: Impacts on plant diversity and evolution. - Proceedings of the National Academy of Sciences 98:54335440.

[75] TØTTRUP, A.P., Larsen, J.L., Burgess, N.D. (2004): A first estimate of the population size of Loveridge's Sunbird Nectarinia loveridgei, endemic to the Uluguru Mountains, Tanzania. - Bird Conservation International 14:25-32.

[76] Townsend Peterson, A., Papeş, M., Eaton, M. (2007): Transferability and model evaluation in ecological niche modeling: a comparison of GARP and Maxent. Ecography 30:550-560.

[77] Wei, W., Mendel, J.M. (2000): Maximum-likelihood classification for digital amplitudephase modulations. Communications, IEEE Transactions on 48:189-193.

[78] Woodward, F.I., Beerling, D.J. (1997): The dynamics of vegetation change: health warnings for equilibrium'dodo'models. - Global Ecology and Biogeography Letters, 413418.

[79] Wu, J., Shen, W., Sun, W., Tueller, P. (2002): Empirical patterns of the effects of changing scale on landscape metrics. - Landscape Ecol 17:761-782.

[80] Ylhäisi, J. (2004): Indigenous forests fragmentation and the signifi cance of ethnic forests for conservation in the North Pare, the Eastern Arc Mountains, Tanzania. FenniaInternational Journal of Geography 182:109-132.

[81] Zotz, G., Bader, M.Y.(2009): Epiphytic Plants in a Changing World-Global: Change Effects on Vascular and Non-Vascular Epiphytes. In: Lüttge, U., Beyschlag, W., Büdel, B., Francis, D. (Eds.), Progress in Botany. Springer Berlin Heidelberg, pp. 147-170. 